\title{
Neoadjuvant chemotherapy should be administered to fit patients with newly diagnosed, potentially resectable muscle-invasive urothelial cancer of the bladder (MIBC): A 2013 CAGMO Consensus Statement and Call for a Streamlined Referral Process
}

\author{
Jo-An Seah, MBBS, BMedSci, FRACP; $;^{*}$ Normand Blais, MD, MSc, FRCPC; ${ }^{\dagger}$ Scott North, MD, FRCPC, MHPE; \\ Yasmin Rahim, MD, FACP, FRCPC, Dean Ruether, MD, FRCPC;, Peter C. Black, MD, FACS, FRCSC,f \\ Alexandre R. Zlotta, MD, PhD, FRCSC,; Lori Wood, MD, MSc(Epi), Srikala S. Sridhar, MD, MSC, FRCPC
}

\begin{abstract}
*Princess Margaret Hospital, Toronto, ON; †Université de Montréal, Chair, Genito-Urinary Oncology Program, CHUM - Hôpital Notre-Dame, Montreal, QC; §Department of Oncology, University of Alberta, Cross Cancer Institute, Edmonton, AB; :Department of Medicine, University of Toronto, Stronach Regional Cancer Centre, Newmarket, ON; * University of Calgary, Cancer Control, Calgary, AB; \& Department of Urologic Sciences, University of British Columbia, Vancouver, BC; $€$ Departments of Medicine and Urology, Dalhousie University, QEll Health Sciences Centre, Halifax, NS
\end{abstract}

See related commentary by Christopher Booth at cuaj.ca.

Cite as: Can Urol Assoc J 2013;7(9-10):312-8. http://dx.doi.org/10.5489/cuaj.1506 Published online October 7, 2013.

\section{Abstract}

Neoadjuvant chemotherapy (NC) improves overall survival in patients with resectable muscle-invasive urothelial cancer of the bladder (MIBC). However uptake of NC in Canada is disappointingly low. Following a detailed literature review and in consultation with urologic oncology, the Canadian Association of Genitourinary Medical Oncologists (CAGMO) has developed a consensus statement for the use of $\mathrm{NC}$ in MIBC. Our primary goal is to increase the uptake of NC for MIBC in Canada and improve patient outcomes.

\section{Introduction}

MIBC is the sixth most common malignancy diagnosed in Canada with 7800 new cases and 2100 cancer-related deaths annually. ${ }^{1}$ At diagnosis, $30 \%$ of patients have muscleinvasive disease, which is defined pathologically as organ confined (pT2), or extravesical disease (pT3 or pT4). ${ }^{2}$ In these patients, despite radical cystectomy (RC) and lymph node dissection only about $50 \%$ of patients are cured and most patients subsequently die of metastatic disease within 3 years of diagnosis. For MIBC patients treated with local therapy alone, the overall survival (OS) rates are $52 \%$ to $77 \%$ for pT2 disease, $40 \%$ to $64 \%$ for pT3 disease, and only $26 \%$ to $44 \%$ for pT 4 or node-positive disease. ${ }^{3}$ Attempts to improve these outcomes have focused not only on improved surgical techniques and use of extended lymph node dissection, but also on the use of perioperative chemotherapy.

All patients with suspected MIBC first require a transurethral resection of the bladder tumour (TURBT) with adequate muscle sampling to confirm the presence of muscle-invasion. Once confirmed, patients with MIBC should be considered for neoadjuvant chemotherapy (NC) which should begin as soon as possible after diagnosis. This recommendation is based on a large meta-analysis of 11 randomized trials of NC, which showed a $5 \%$ OS benefit with cisplatin-based combination regimens. ${ }^{4}$ Close follow-up (clinical and radiographic) during $\mathrm{NC}$ is crucial to monitor for toxicity and/or disease progression that may necessitate early discontinuation of NC and definitive local management. After NC is complete, and once blood counts are adequate, patients should undergo RC and lymph node dissection. For patients who are not surgical candidates, bladder sparing approaches may also be an option after NC; however, a comprehensive discussion of bladder preservation is beyond the scope of this article.

Where NC is not an option, or if patients have already had definitive surgery adjuvant chemotherapy (AC) administered in a timely manner post surgery can be considered. The 2005 Advanced Bladder Cancer (ABC) meta-analysis systemically reviewed 6 adjuvant trials and though limited by small patient numbers and imbalances between patient groups, did show a $25 \%$ relative risk reduction in death. ${ }^{5}$ There was however, insufficient evidence to recommend AC over NC which remains the preferred option.

Despite Level 1 evidence for NC, several studies including a Canadian survey of medical oncologists have shown 


\begin{tabular}{|c|c|c|c|c|c|}
\hline Author/year & No. patients & Stage & NC regimen & Definitive treatment & OS benefit \\
\hline Wallace $/ 1991^{29}$ & 159 & T2-4NXMO & Cisplatin $100 \mathrm{mg} / \mathrm{m}^{2}$ & $45-50 \mathrm{~Gy}$ in $22 \mathrm{~F}$ & No \\
\hline Raghavan/199130 & 96 & T2-4NXM0 & Cisplatin $70 \mathrm{mg} / \mathrm{m}^{2}$ & $\begin{array}{c}65 \mathrm{~Gy} \text { in } 22 \mathrm{~F}+ \\
\mathrm{RC}+\text { pelvic } \\
\text { lymphadenectomy }\end{array}$ & No \\
\hline Martinez-Pineiro/1995 ${ }^{31}$ & 122 & T2-4ANX-2M0 & Cisplatin $100 \mathrm{mg} / \mathrm{m}^{2}$ & $\begin{array}{c}\mathrm{RC}+\text { pelvic } \\
\text { lymphadenectomy }\end{array}$ & No \\
\hline Malmstrom/1996 32 & 325 & $\begin{array}{c}\text { T1 (grade3) } \\
\text { T2-4A } \\
\text { NXM0 }\end{array}$ & $\begin{array}{c}\text { Cisplatin } 70 \mathrm{mg} / \mathrm{m}^{2} \\
\text { Doxorubicin } 30 \mathrm{mg} / \mathrm{m}^{2}\end{array}$ & $\begin{array}{c}20 \mathrm{~Gy} \text { in } 5 \mathrm{~F} \\
+\mathrm{RC}+\text { pelvic } \\
\text { lymphadenectomy }\end{array}$ & $\begin{array}{l}\text { Yes for T3-T4 } \\
\qquad(p=0.03)\end{array}$ \\
\hline Abol-Enein $/ 1997^{33}$ & 196 & T2-4ANXM0 & $\begin{array}{l}\text { Carboplatin } 300 \mathrm{mg} / \mathrm{m}^{2} \\
\text { Methotrexate } 50 \mathrm{mg} / \mathrm{m}^{2} \\
\text { Vinblastine } 4 \mathrm{mg} / \mathrm{m}^{2}\end{array}$ & $\begin{array}{c}R C+\text { pelvic } \\
\text { lymphadenectomy }\end{array}$ & Not reported \\
\hline Bassi/199934 & 206 & T2-4NOMO & $\begin{array}{l}\text { Cisplatin } 70 \mathrm{mg} / \mathrm{m}^{2} \\
\text { Methotrexate } 30 \mathrm{mg} / \mathrm{m}^{2} \\
\text { Vinblastine } 3 \mathrm{mg} / \mathrm{m}^{2}\end{array}$ & $\begin{array}{c}\mathrm{RC}+\text { pelvic } \\
\text { lymphadenectomy }\end{array}$ & Not reported \\
\hline $\begin{array}{l}\text { International } \\
\text { Collaboration/1999, }{ }^{7} \text { updated } \\
2011^{8}\end{array}$ & 976 & $\begin{array}{c}\text { T2 (grade 3) } \\
\text { T3-T4A } \\
\text { NO,NXMO }\end{array}$ & $\begin{array}{l}\text { Cisplatin } 100 \mathrm{mg} / \mathrm{m}^{2} \\
\text { Vinblastine } 4 \mathrm{mg} / \mathrm{m}^{2} \\
\text { Methotrexate } 30 \mathrm{mg} / \mathrm{m}^{2}\end{array}$ & $\begin{array}{l}60 \mathrm{~Gy} \text { in } 30 \mathrm{~F} \text { (or) } \\
20 \mathrm{~Gy} \text { in } 5 \mathrm{~F}+\mathrm{RC} \\
\text { (or) } \mathrm{RC} \text { and pelvic } \\
\text { lymphadenectomy }\end{array}$ & $\begin{array}{c}\text { Yes on } 2011 \\
\text { update } \\
(p=0.037)\end{array}$ \\
\hline Sherif/2002 35 & 317 & T2-4ANXM0 & $\begin{array}{c}\text { Cisplatin } 100 \mathrm{mg} / \mathrm{m}^{2} \\
\text { Methotrexate } 250 \mathrm{mg} / \mathrm{m}^{2}\end{array}$ & $\begin{array}{c}\mathrm{RC}+\text { pelvic } \\
\text { lymphadenectomy }\end{array}$ & No \\
\hline Sengelov/2002 36 & 153 & $\begin{array}{l}\text { T2-T4b } \\
\text { NONX } \\
\text { MO }\end{array}$ & $\begin{array}{c}\text { Cisplatin } 100 \mathrm{mg} / \mathrm{m}^{2} \\
\text { Methotrexate } 250 \mathrm{mg} / \mathrm{m}^{2}\end{array}$ & $60 \mathrm{~Gy}$ in $30 \mathrm{~F}$ (or) RC & $\begin{array}{c}\text { No } \\
(p=0.76)\end{array}$ \\
\hline Cortesi/unpublished & 171 & T2-4NOMO & $\begin{array}{l}\text { Cisplatin } 70 \mathrm{mg} / \mathrm{m}^{2} \\
\text { Methotrexate } 30 \mathrm{mg} / \mathrm{m}^{2} \\
\text { Vinblastine } 3 \mathrm{mg} / \mathrm{m}^{2} \\
\text { Epirubicin } 40 \mathrm{mg} / \mathrm{m}^{2}\end{array}$ & $\mathrm{RC}$ & $\begin{array}{c}\text { Not } \\
\text { reported }\end{array}$ \\
\hline Grossman $/ 2003^{9}$ & 317 & $\begin{array}{l}\text { T2-T4A } \\
\text { NXM0 }\end{array}$ & $\begin{array}{l}\text { Methotrexate } 30 \mathrm{mg} / \mathrm{m}^{2} \\
\text { Vinblastine } 3 \mathrm{mg} / \mathrm{m}^{2} \\
\text { Doxorubicin } 30 \mathrm{mg} / \mathrm{m}^{2} \\
\text { Cisplatin } 70 \mathrm{mg} / \mathrm{m}^{2}\end{array}$ & $\mathrm{RC}$ & $\begin{array}{c}\text { No } \\
(p=0.06)\end{array}$ \\
\hline
\end{tabular}

that referrals for and uptake of $\mathrm{NC}$ remains low. ${ }^{6}$ To improve the uptake of $\mathrm{NC}$, coordination of $\mathrm{NC}$ and definitive surgical management is essential and requires a streamlined referral process and close multidisciplinary collaboration.

The aims of this CAGMO initiative were therefore to:

1) Conduct a literature review on NC in MIBC and understand barriers to its use.

2) Develop a consensus statement on the use of $\mathrm{NC}$ in MIBC, informed by input from medical and urologic oncology.

3) Publish a consensus statement advocating for the use of NC in Canada.

4) Assess the impact of this consensus statement, on the uptake of NC for MIBC in Canada, 12 months postpublication.

\section{Methods}

Following the 2012 CAGMO Annual Meeting, where challenges relating to bladder cancer care were identified, a consensus statement on the use of NC in MIBC was drafted and circulated to a core group of medical oncologists (SS, LW, SN, NB, and DR). The document was then reviewed with two urologic oncologists (AZ and PB) and is presented here. Twelve months post-publication of this consensus statement a survey to assess uptake of NC in Canada will be administered.

\section{Discussion}

\section{Neoadjuvant chemotherapy for bladder MIUC}

The practice of $\mathrm{NC}$ is well-established in treating many malignancies, resulting in tumour downsizing and improved outcomes In MIBC, RC, with curative intent, is associated with a high failure rate, and provides the impetus to use perioperative systemic chemotherapy to improve outcomes. ${ }^{3}$ Level 1 evidence supports the use of NC in MIBC, with an OS benefit. There have been several randomized clinical trials evaluating the use of neoadjuvant platinum-based regimens in MIBC (Table 1); 3 key trials are highlighted below. 
Seah et al.

In the EORTC/MRC Phase III international multi-institutional trial, 976 patients with T2-T4a N0 or NX M0 disease (of which $58 \%$ were T3) were randomized to 3 cycles of cisplatin, methotrexate and vinblastine (CMV) followed by definitive local therapy ( $\mathrm{RC}$ and/or radiotherapy) or definitive therapy alone. ${ }^{7}$ Although initially reported as a negative trial, with longer follow-up NC showed a statistically significant $16 \%$ reduction in risk of death (hazard ratio [HR] 0.84, 95\% confidence interval [Cl], 0.72-0.99, $p=0.037)$; improvement in 3-year OS from 50-56\%; 10-year OS from 30\% to $36 \%$; and median survival from 37 to 44 mos. ${ }^{7,8}$

These results are similar to the Southwest Oncology Group (SWOG) trial reported by Grossman and colleagues, in which 317 patients with clinical stage T2-T4a, N0, M0 (of which $60 \%$ were T3 or T4a), were randomized to 3 cycles of methotrexate, vinblastine, adriamycin and cisplatin (MVAC) followed by RC or RC alone. NC showed a statistically significant $25 \%$ reduction in risk of death (HR $0.75,95 \% \mathrm{Cl}$, $0.57-1.0, p=0.06$ ); and improved median survival from 46 to 77 months. Importantly, $38 \%$ of patients receiving NC had no residual invasive disease (pT0) at the time of cystectomy compared to only $15 \%$ in the group who did not have NC $(p<0.001)$. Furthermore, $85 \%$ of patients who were pT0 at cystectomy were alive at 5 years. There were no toxic deaths or increase in postoperative complications in patients who received NC. ${ }^{9}$

Although some of the NC trials were small, did not use cisplatin-based combination regimens, closed early, or used different local therapies ( $\mathrm{RC}$ and/or radiation) a large metaanalysis by the $\mathrm{ABC}$ Collaboration has confirmed an OS benefit of NC (Table 1). The 2003 meta-analysis reviewed data from 2688 individual patients and 10 randomized clinical trials of platinum-based NC for biopsy-proven cT2-cT4A MIBC. They showed an absolute OS benefit of $5 \%$ at 5 years, with OS increasing from $45 \%$ to $50 \%$, regardless of the type of definitive local therapy, which included RC, radiotherapy, and combined RC and radiotherapy. This analysis did not suggest improved OS with single agent cisplatin, and it was not possible to assess the effect of carboplatinbased versus cisplatin-based regimens. ${ }^{10}$ An updated $A B C$ Meta-Analysis in 2005 including the SWOG trial discussed above, confirmed the $5 \%$ absolute survival improvement $(p=0.003)$ and $9 \%$ improvement in disease-free survival at 5 years $(p<0.0001) .{ }^{4}$ Unfortunately, toxicity and quality of life were not assessed in these meta-analyses (Table 1).

\section{Advantages of NC}

There are a number of potential advantages of $\mathrm{NC}$, including:

- Improved overall survival (Level 1 evidence).

- Down-staging of the primary tumour which may facilitate surgery.
- In vivo assessment of chemo-sensitivity.

- Treatment of micro-metastatic disease (postulated to be the reason for the survival benefit).

- Improved tolerability of chemotherapy prior to RC. Postoperatively, $64 \%$ of patients may experience complications within 90 days of RC, and as a result up to $30 \%$ may be unable to receive chemotherapy postoperatively due to these complications. ${ }^{11} \mathrm{NC}$ may, therefore, be more feasible than $\mathrm{AC}$ and result in more patients receiving the benefit of systemic treatment.

- The fact that there is no evidence of a detrimental effect in delaying RC for chemotherapy administration, ${ }^{12}$ and RC ideally within 4 to 6 weeks of completing NC but within 10 weeks of NC, is feasible without compromising survival. ${ }^{13}$

\section{Disadvantages of NC may include:}

- Potential for disease progression in patients with chemo-resistant disease; however, with close clinical monitoring and restaging scans performed after 2 cycles of NC, definitive RC can be performed in a timely manner in patients not responding to NC.

- NC-related complications, such as infections, which may potentially delay RC. Increased risk of post-RC complications after exposure to NC; however, these concerns have not been borne out by reports of surgical morbidity. ${ }^{14-17}$

\section{Chemotherapy regimens for NC}

The optimum NC regimen is unknown, although standard MVAC is the regimen with the most robust evidence. Dose-dense MVAC (ddMVAC) given every 2 weeks, with growth-factor support is also a reasonable option. GC (gemcitabine and cisplatin) is the most commonly used regimen in Canada although it lacks prospective randomized Phase III data in support of its use. The efficacy and use of GC in the neoadjuvant setting is extrapolated from the metastatic setting, where Phase III data showed similar efficacy, but less toxicity compared with MVAC. ${ }^{18}$ In the neoadjuvant setting, as with other cancers, pathological down-staging appears to be an important surrogate endpoint, where patients who have no residual invasive disease at the time of RC have improved survival. ${ }^{19}$ Neoadjuvant MVAC has shown a pathological down-staging (to pT0) rate of $38 \%$, which is the highest reported to date. A recent pooled analysis of 7 studies published from 2007 to 2012 evaluated clinical outcomes with neoadjuvant GC $(n=164$ patients) and revealed pathological down-staging to pT0 and to less than pT2 rates of $26 \%$ and $47 \%$ of patients, respectively. ${ }^{20}$ Despite the challenges of cross trial compari- 
sons and acknowledging that these results appear inferior to the results from neoadjuvant MVAC, $57 \%$ of patients receiving MVAC experienced grade 3/4 granulocytopenia, as compared to $38 \%$ who experienced grade $3 / 4$ haematological toxicities with neoadjuvant GC. ${ }^{9,20}$ Therefore, the better toxicity profile of GC makes it a reasonable option despite the lack of strong evidence.

In metastatic disease, substituting carboplatin for cisplatin in cisplatin-unfit patients (those with multiple comorbidities, poor functional status or renal impairment) is a common practice. However, the $A B C$ meta-analyses only included 1 trial with a carboplatin-containing regimen versus 10 trials with cisplatin-based protocols. ${ }^{4}$ There is therefore no evidence to support the use of carboplatin in the neoadjuvant setting, and thus carboplatin cannot be recommended. Cisplatin-unfit patients should forego NC and proceed immediately to definitive local therapy.

\section{Patient selection for NC}

Selection of patients for NC requires careful assessment of both functional status and comorbidities (in particular presence of renal impairment) that may preclude safe administration of cisplatin-based combination chemotherapy. In addition it may be important to address the anxieties related to deferred surgery.

The published meta-analyses show an OS benefit in all subgroups with T2-T4 disease. However, trials within the meta-analyses did not include clinically node-positive bladder cancers or upper tract UC. ${ }^{4}$ We believe extrapolation of data to patients with upper tract UC is reasonable (Level 3 evidence, expert opinion), and an informed discussion with these patients on an individualized basis about the benefits and risks of NC is appropriate. Unfortunately, there is no data from prospective, randomized controlled trials of upper tract UC (including that of ureteral disease) to inform such a discussion. Given the obligatory loss of renal function following radical nephroureterectomy, if systemic perioperative chemotherapy is to be considered, it would seem most feasible to be administered prior to surgery. ${ }^{21}$ Pure non-urothelial cancers were also not represented in the trials, and there is no data to support perioperative chemotherapy for non-UCs of the urothelial tract, unless a component of urothelial histology is present. This highlights the importance of accurate uro-pathological reporting about histological variants, as this not only influences whether NC should be administered or not, but it also has been shown to be a strong independent predictor of upstaging at time of RC. ${ }^{22}$

\section{Barriers to NC and reasons for poor uptake}

Despite Level 1 evidence for the use of NC for MIBC, the incorporation of $\mathrm{NC}$ as part of standard practice has proven to be quite challenging across North America. In a large retrospective study, Feifer and colleagues analyzed all T2-4 NOMO MIBC patients (4541 patients from 14 academic institutions) undergoing RC from 2003 to 2008. They found $66 \%$ of potentially eligible patients undergoing RC did not receive perioperative chemotherapy. Only $12 \%$ of patients received $\mathrm{NC}$, and $35 \%$ of those patients received non-cisplatin based regimens. ${ }^{23}$ Low uptake of $\mathrm{NC}$ was also found in two retrospective Canadian studies. In a study by Yafi and colleagues, of 2287 patients treated with RC between 1998 and 2008 , only $3.1 \%$ of patients received NC while $19.4 \%$ received $A C .{ }^{24} \mathrm{~A}$ study by Booth and colleagues, of 2738 MIBC patients treated with RC between 1994 and 2008 showed NC rates to be $3 \%$ to $6 \%$ and $A C$ rates to be $16 \%$ to $23 \% .{ }^{25}$ Although in some cases there are reasons to avoid NC (such as preoperative renal dysfunction, poor performance status, and symptomatic disease), these studies do suggest a significant number of eligible patients are not being offered NC.

There are likely several reasons to explain the low uptake of NC. In a study reported by Raj and colleagues, among 145 patients who underwent RC for preoperative clinical stage $\geq \mathrm{T} 2$ disease, where only $17 \%$ received cisplatin-based $\mathrm{NC}$, the main reasons cited for lack of use were age, comorbidities, concerns over toxicity and the modest nature of benefit. ${ }^{26}$ This latter point may particularly be an issue in patients with clinically staged, cT2 disease where the relative benefit from NC appears smaller compared to that of T3 or T4a disease, but nevertheless there is still a 5\% OS benefit at 5 years. Another reason to offer NC to patients with cT2 disease is that a significant number of patients are upstaged at the time of RC. Contemporary series show that up to $73 \%$ of patients with cT2 disease are actually upstaged at $\mathrm{RC}_{1}{ }^{27}$ and as such may derive greater relative benefit from $\mathrm{NC}$ than initially expected preoperatively. Encouraging data from a recent Canadian survey of medical oncologists and urologists suggests that $96 \%$ and $88 \%$, respectively would offer NC, however the referral rate and use of NC is still relatively low. ${ }^{6,28}$ This may be due to a lack of a multidisciplinary approach up front, and could possibly be addressed by the implementation of a streamlined referral process which ensures referrals to medical oncology, timely completion of $\mathrm{NC}$ and subsequent $\mathrm{RC}$ or where appropriate, bladder sparing therapies.

As Canadian medical oncologists treating urothelial cancer, CAGMO feels it is imperative that all patients with potentially resectable MIBC without contraindications for cisplatin-based combination chemotherapy should be considered for NC. 
Seah et al.

\section{Appendix 1. CAGMO Position Statement}

General introduction

- Level I evidence supports NC in potentially resectable MIBC to improve OS.

- All patients with MIBC that meet eligibility criteria (below) should be referred to medical oncology.

- Patients who do not meet eligibility criteria, or whose disease progress while receiving NC, should proceed to definitive local therapy, such as RC, after the resolution of relevant chemotherapy toxicities.

- Timely management in a multidisciplinary environment is crucial and is dependent upon good communication between urologists, medical oncologists and radiation oncologists.

\section{Eligibility for neoadjuvant chemotherapy}

1) UC of the upper tract, bladder and urethra, including mixed squamous and/or glandular differentiation, but excluding other histologic subtypes such as micropapillary or sarcomatoid carcinoma.

2) Preoperative clinical stage T2-T4a NOMO (resectable, non-metastatic disease).

3) ECOG (Eastern Cooperative Oncology Group) performance status 0-1.

4) Creatinine clearance $\geq 50 \mathrm{~mL} / \mathrm{min}$.

\section{Caveats}

1) N1 patients do not meet the criteria for NC and have not been included in Phase III clinical trials. Some of these patients may benefit from a combination of systemic and local therapies (surgery or radiation).

2) Upper tract and urethral were not included in the Phase III clinical trials. These patients have poor outcomes and may benefit from combined systemic and surgical therapy based on extrapolation from the experience with MIBC.

\section{Exclusion criteria}

1) Significant comorbidities or $E C O G \geq 2$.

2) Overwhelming lower urinary tract symptoms or patients who require immediate local management for symptom control.

\section{Caveats}

1) Such patients warrant discussion with a medical oncologist as these are not absolute contraindications to NC.

2) Lower urinary tract symptoms, including hematuria, may improve with NC.

Treated urinary sepsis is not a contraindication to NC.

\section{Staging}

1) Before and within 4 to 6 weeks of starting NC to assess treatment response. Baseline computed tomography (CT) of the chest/abdomen/ pelvis (with contrast ideally where renal function is adequate) at the time of TURBT and suspected MIBC $\geq T 2$ to rule out nodal and distant metastatic disease.

2) Pelvic magnetic resonance imaging (ideally with contrast) if CT staging is contraindicated.

3) Bone scan if hypercalcaemia, elevated alkaline phosphatase (ALP), or concerning symptoms.

4) Baseline assessment of blood counts, renal function, electrolytes, calcium, magnesium, liver enzymes (including ALP).

\section{Chemotherapy options}

1) Standard MVAC: every 28 days; 3 cycles (a total of 12 weeks) (Level 1 evidence).

2) GC: Days 1 and 8, every 21 days; 4 cycles (a total of 12 weeks) (Level 3 evidence).

ddMVAC with granulocyte-colony stimulating factor (G-CSF) support: every 14 days; 4 cycles (a total of 8 weeks) (Level 3 evidence).

\section{Caveats}

1) NC should start as soon as possible, ideally within 1 to 2 weeks of medical oncology consultation. RC within 12 weeks of TURBT has been shown to have improved outcomes; while there is no evidence-based data with regard to optimal timing of starting NC postTURBT, it is reasonable to extrapolate that earlier treatment leads to better outcomes.

2) Ensure reversible causes of low creatinine clearance are addressed (especially decompression of hydronephrosis). Patients with borderline creatinine clearance $(50-60 \mathrm{~mL} / \mathrm{min})$ may be able to receive cisplatin using split dosing regimens, where the cisplatin dose is divided, and administered on day 1 and day 8 (or less commonly day 1 and 2) with gemcitabine on day 1 and 8 . Immediate RC is recommended in those patients not eligible for cisplatin-based NC. If RC is not possible or desired, bladder preservation therapy with radiation where appropriate may be considered.

\section{Monitoring during neoadjuvant chemotherapy}

1) Patients receiving NC are assessed prior to every cycle with a clinical assessment and blood work.

2) Restaging CT scans (ideally with contrast where kidney function is appropriate) are performed after 2 cycles of NC. Radiological or clinical evidence of progression should lead to discontinuation of NC and timely RC once blood counts are adequate..

3) Repeat cystoscopy may be required during NC if urinary symptoms progress, or if there is concern about progressive disease within the bladder.

4) Surgical follow-up is required around the commencement of the last cycle of NC to facilitate timely access to the operating room within 4 to 6 weeks of chemotherapy completion. Bladder preservation therapy may be appropriate for carefully selected patients.

5) Restaging scans may be performed upon completion of NC prior to surgery 


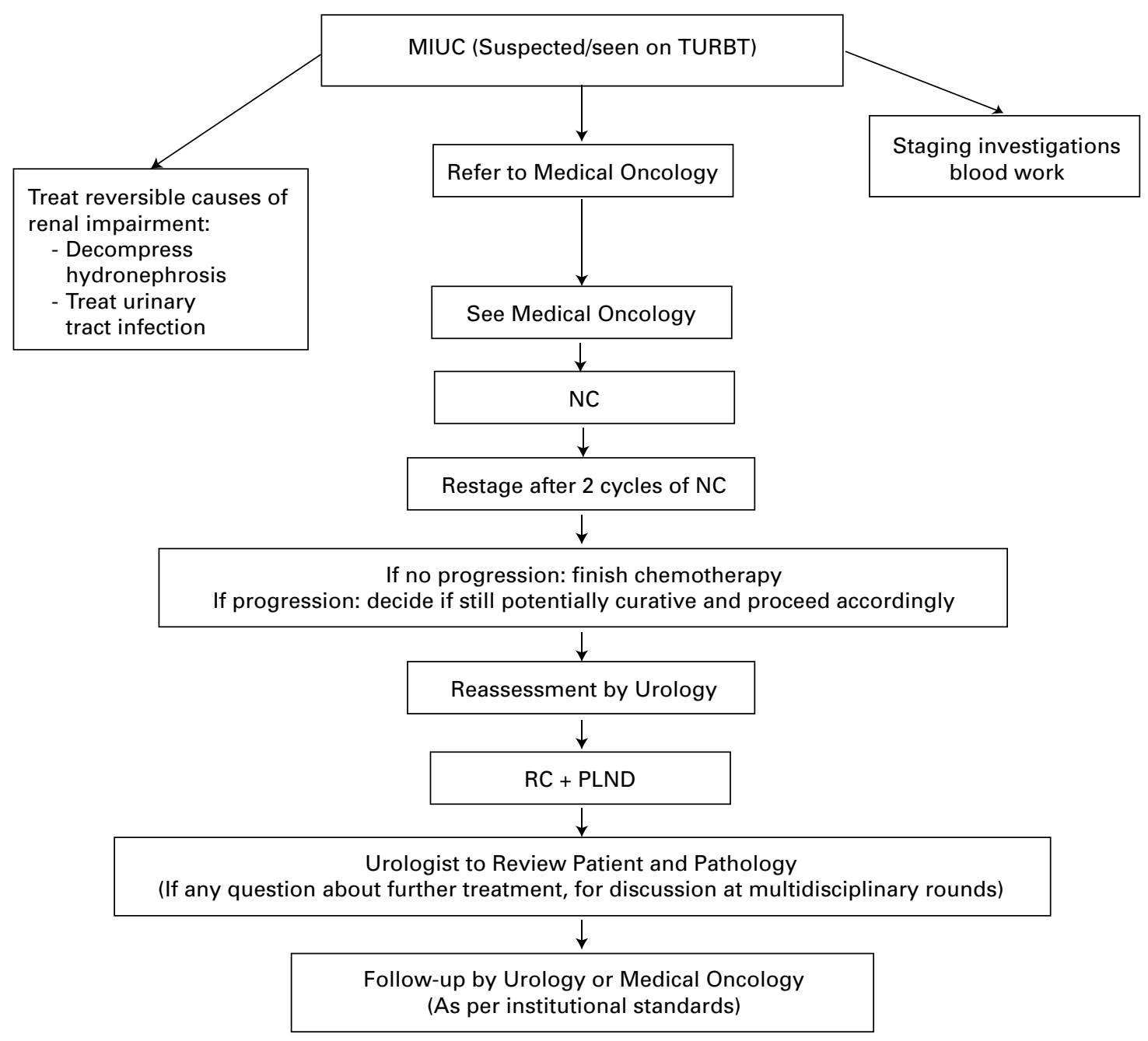

Fig. 1. Patient flow from initial transurethral resection of bladder tumour to follow-up with a target timelines. TURBT: transurethral resection of the bladder tumour; NC: neoadjuvant chemotherapy; RC: radical cystectomy; PLND: pelvic lymph node dissection.

Target timelines:

I. TURBT to Pathology Review and Urology Review: 2 weeks.

II. Urology to Medical Oncology: 2 weeks.

III. Medical Oncology to commencement of NC: As soon as possible, maximum of 2 weeks.

IV. Completion of NC to definitive surgical management: within 4-6 weeks.

\section{Conclusion}

Despite Level 1 evidence of improved patient outcomes associated with NC for MIBC, the uptake of NC in Canada and internationally remains disappointingly low. NC is feasible, safe, and when delivered in a timely manner does not negatively affect surgical outcomes. Patients do require close monitoring and follow-up medically and surgically while on treatment to address toxicities and potential disease progression; this ensures the best outcomes for all patients.

Referral processes and lack of coordinated care in a multidisciplinary setting are barriers that can be overcome. CAGMO acknowledges that as we dig deeper for reasons why NC uptake in this setting is poor, the answers are likely more complex than it appears at first sight. CAGMO strongly recommends the establishment of a streamlined referral processes and excellent interdisciplinary communication in a team environment, as well as the consideration of $\mathrm{NC}$ for all patients with MIBC to optimize patient outcomes. It is our hope that this 2013 CAGMO Consensus Statement will facilitate these developments in Canada.

\section{References}

1. Canadian Cancer Society. Bladder Cancer Statistics; 2012. http://www.cancer.ca/en/cancer-information/cancer-type/bladder/statistics/?region=on. Accessed September 11, 2013. 
Seah et al.

2. Rosenberg JE, Carroll PR, Small EJ. Update on chemotherapy for advanced bladder cancer. J Urol 2005;174:14-20. http://dx.doi.org/10.1097/01.ju.0000162039.38023.5f

3. Stein JP, Lieskovsky $G$, Cote R, et al. Radical cystectomy in the treatment of invasive bladder cancer: long-term results in 1,054 patients. J Clin Oncol 2001;19:666-75.

4. Advanced Bladder Cancer (ABC) Meta-analysis Collaboration. Neoadjuvant chemotherapy in invasive bladder cancer: update of a systematic review and meta-analysis of individual patient data advanced bladder cancer (ABC) meta-analysis collaboration. Eur Urol 2005;48:202-5; discussion 205-6. http:// dx.doi.org/10.1016/i.eururo.2005.04.006

5. Advanced Bladder Cancer (ABC) Meta-analysis Collaboration. Adjuvant chemotherapy in invasive bladder cancer: a systematic review and meta-analysis of individual patient data Advanced Bladder Cancer (ABC) Meta-analysis Collaboration. Eur Urol 2005;48:189-99; discussion 199-201. http://dx.doi. org/10.1016/i.eururo.2005.04.005

6. T. Hsu, S. North, B. J. Eigl, K. N. Chi, C. M. Canil, L. Wood, A. Lau, T. Panzarella, S. S. Sridhar. The neoadjuvant management of bladder cancer in Canada: A survey of genitourinary medical oncologists. J Clin Oncol 29: 2011 (supp 17; 285)

7. International Collaboration of trialists, MRC/EORTC et al: Neoadjuvant cisplatin, methotrexate, and vinblastine chemotherapy for muscle-invasive bladder cancer: a randomised controlled trial. Lancet 1999;354:533-40. http://dx.doi.org/10.1016/S0140-6736(99)02292-8

8. International Collaboration of Trialists, MRC/EORTC et al; International phase III trial assessing neoadiuvant cisplatin, methotrexate, and vinblastine chemotherapy for muscle-invasive bladder cancer: long-term results of the BA06 30894 trial. J Clin Oncol 2011 Jun 1;29(16):2171-7. doi: 10.1200/JC0.2010.32.3139.

9. Grossman HB, Natale RB, Tangen $C M$, et al. Neoadjuvant chemotherapy plus cystectomy compared with cystectomy alone for locally advanced bladder cancer. N Engl J Med 2003;349:859-66. http://dx.doi. org/10.1056/NEJMoo022148

10. Advanced Bladder Cancer (ABC) Meta-analysis Collaboration. Neoadjuvant chemotherapy in invasive bladder cancer: a systematic review and meta-analysis. Lancet 2003 Jun 7;361 (9373):1927-34.

11. Donat SM, Shabsigh A, Savage C, et al Potential impact of postoperative early complications on the timing of adjuvant chemotherapy in patients undergoing radical cystectomy: a high-volume tertiary cancer center experience. Eur Urol 2009 Jan;55(1):177-85. doi: 10.1016/i.eururo.2008.07.018.

12. Izawa Jl, Chin JL, Winquist E. Timing cystectomy and perioperative chemotherapy in the treatment of muscle invasive bladder cancer. Can J Urol 2006 Jun; 13 Suppl 3:48-53.

13. Alva AS, Tallman CT, He C, et al. Efficient delivery of radical cystectomy after neoadjuvant chemotherapy for muscle-invasive bladder cancer: a multidisciplinary approach. Cancer 2012 Jan 1; 118(1):44-53. doi: 10.1002/cncr.26240. Epub 2011 May 19.

14. Hall MC, Swanson DA, Dinney CP. Complications of radical cystectomy: impact of the timing of perioperative chemotherapy. Urology 1996;47:826-30. http://dx.doi.org/10.1016/S0090-4295(96)00073-8

15. Lawrentschuk N, Colombo R, Hakenberg OW, et al. Prevention and management of complications following radical cystectomy for bladder cancer. Eur Urol 2010;57:983-1001. http://dx.doi.org/10.1016/i. eururo.2010.02.024

16. Svatek RS, Fisher MB, Matin SF, et al. Risk factor analysis in a contemporary cystectomy cohort using standardized reporting methodology and adverse event criteria. J Urol 2010;183:929-34. http://dx.doi. org/10.1016/i.uro.2009.11.038

17. Svatek RS, Fisher MB, Williams MB, et al. Age and body mass index are independent risk factors for the development of postoperative paralytic ileus after radical cystectomy. Urology 2010;76:1419-24. http://dx.doi.org/10.1016/i.urology. 2010.02.053

18. von der Maase H, Sengelov L, Roberts JT, et al. Long-term survival results of a randomized trial comparing gemcitabine plus cisplatin, with methotrexate, vinblastine, doxorubicin, plus cisplatin in patients with bladder cancer. J Clin Oncol 2005;23:4602-8. http://dx.doi.org/10.1200/JC0.2005.07.757

19. Rosenblatt $R$, Sherif $A$, Rintala $E$, et al. Pathologic downstaging is a surrogate marker for efficacy and increased survival following neoadiuvant chemotherapy and radical cystectomy for muscle-invasive urothelial bladder cancer. Eur Urol 2012;61:1229-38. http://dx.doi.org/10.1016/i.eururo.2011.12.010
20. Yuh BE, Ruel N, Wilson TG, et al. Pooled analysis of clinical outcomes with neoadiuvant Cisplatin and gemcitabine chemotherapy for muscle invasive bladder cancer. J Urol 2013;189:1682-6. http://dx.doi. org/10.1016/i.juro.2012.10.120

21. Green DA, Rink M, Xylinas E, et al. Urothelial carcinoma of the bladder and the upper tract: disparate twins. J Urol 2013;189:1214-21. http://dx.doi.org/10.1016/i.juro.2012.05.079

22. Turker P, Bostrom PJ, Wroclawski ML, et al. Upstaging of urothelial cancer at the time of radical cystectomy: factors associated with upstaging and its effect on outcome. BJU Int 2012;110:804-11.

23. Feifer A, Taylor JM, Shovery M, et al. Muscle-invasive Bladder Cancer Quality of Care Consortium, Multiinstitutional quality-of-care initiative for nonmetastatic, muscle-invasive, transitional cell carcinoma of the bladder: Phase I. J Clin Oncol 2011;29 (7Suppl):240.

24. Yafi FA, Aprikian AG, Chin JL, et al. Contemporary outcomes of 2287 patients with bladder cancer who were treated with radical cystectomy: a Canadian multicentre experience. BJU Int 2010;108:539-45. http://dx.doi.org/10.1111/j.1464-410X.2010.09912.x

25. Booth CM, Siemens RD, Li G, et al. Neoadjuvant (NACT) and Adjuvant Chemotherapy (ACT) for MuscleInvasive Bladder Cancer: A Population-Based Outcomes Study. Ann Oncol (2012) 23 (suppl 9;7880): ix258-ix293. doi: 10.1093/annonc/mds399

26. Raj GV, Karavadia S, Schlomer B, et al. Contemporary use of perioperative cisplatin-based chemotherapy in patients with muscle-invasive bladder cancer. Cancer 2011 Jan 15;117(2):276-82. doi: 10.1002/ cncr.25429. Epub 2010 Sep 9 .

27. Canter D, Long C, Kutikov A, et al. Clinicopathological outcomes after radical cystectomy for clinical T2 urothelial carcinoma: further evidence to support the use of neoadjuvant chemotherapy. BJU Int 2011;107:58-62. http://dx.doi.org/10.1111/i.1464-410X.2010.09442.x

28. Sridhar SS, Chi KN, North SA et al. The neoadjuvant management of muscle-invasive bladder cancer (MIBC) in Canada: A national survey of urologists. J Clin Oncol 30, 2012 (suppl 5; 303)

29. Wallace DM, Raghavan D, Kelly KA, et al. Neo-adjuvant (pre-emptive) cisplatin therapy in invasive transitional cell carcinoma of the bladder. Br J Urol 1991;67:608-15.

30. Raghavan D, Pearson B, Watt WH, et al. Cytotoxic chemotherapy for advanced bladder cancer: cisplatincontaining regimens. Semin Oncol 1991;18(1 Suppl 3):56-63.

31. Martinez-Piñeiro JA, Gonzalez Martin M, Arocena F, et al. Neoadjuvant cisplatin chemotherapy before radical cystectomy in invasive transitional cell carcinoma of the bladder: a prospective randomized phase III study. J Urol 1995;153(3 Pt 2):964-73.

32. Malmström PU, Rintala E, Wahlqvist R, et al. Five-year followup of a prospective trial of radical cystectomy and neoadjuvant chemotherapy: Nordic Cystectomy Trial I. The Nordic Cooperative Bladder Cancer Study Group. J Urol 1996;155:1903-6.

33. Abol-Enein $\mathrm{H}$, El-Mekrech $M$, El-Baz $M$, et al. Neoadjuvant chemotherapy in the treatment of invasive transitional bladder cancer. A controlled prospective randomized study. Br J Urol 1997;80:abstract 191.

34. Bassi P, Ferrante GD, Piazza N, et al. Prognostic factors of outcome after radical cystectomy for bladder cancer: a retrospective study of a homogeneous patient cohort. J Urol 1999;161:1494-7.

35. Sherif A, Rintala E, Mestad O, et al. Neoadjuvant cisplatin-methotrexate chemotherapy for invasive bladder cancer-Nordic cystectomy trial 2. Scand J Urol Nephrol 2002;36:419-25.

36. Sengeløv L, von der Maase $\mathrm{H}$, Lundbeck F, et al. Neoadjuvant chemotherapy with cisplatin and methotrexate in patients with muscle-nnvasive bladder tumours. Acta Oncol 2002;41:447-56.

Correspondence: Dr. Lori Wood, QEll Health Sciences Centre, 3064 Highway 2, Halifax, NS B2T 1E6; lori.wood@cdha.nshealth.ca; and Dr. Srikala Sridhar, 522-610 University Ave, Princess Margaret Hospital, Toronto, ON M5G 2M9; srikala.sridhar@uhn.ca 